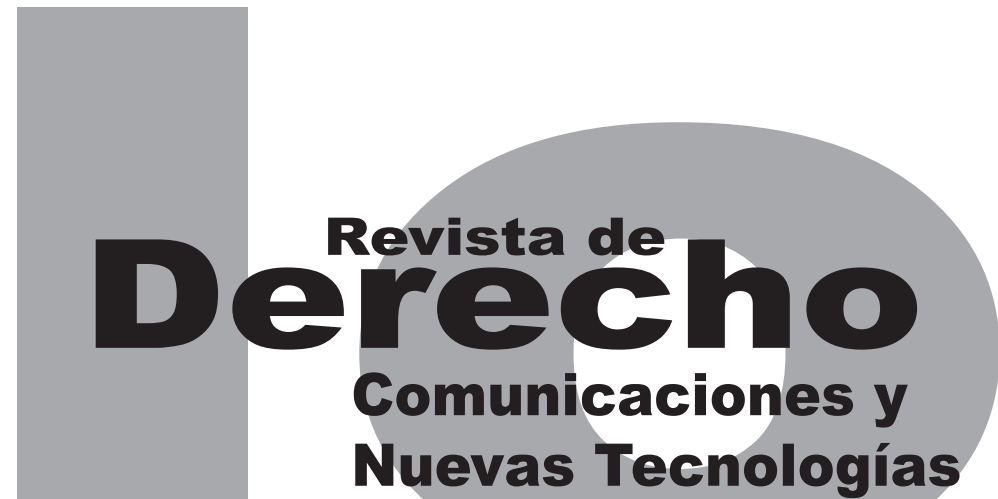

\title{
DE LA EXTRACCIÓN Y EXPLOTACIÓN DE RECURSOS NATURALES EN EL ESPACIO ULTRATERRESTRE, LA LUNA Y LOS CUERPOS CELESTES. UNA REGULACIÓN JURÍDICA
}

\author{
Amelia Piñeros TORRes
}

Artículo de revisión

DOI: http://dx.doi.org/10.15425/redecom.12.2014.04

\author{
Universidad de los Andes \\ Facultad de Derecho
}

Revista de Derecho, Comunicaciones y Nuevas Tecnologías

No.12, Julio - Diciembre de 2014. ISSN 1909-7786 


\title{
De la extracción y explotación de recursos naturales en el espacio ultraterrestre, la Luna y los cuerpos celestes. Una regulación jurídica
}

\section{Resumen}

El objetivo de este trabajo es analizar las fallas que se han presentado en las disposiciones del artículo 11 del Acuerdo que debe regir las actividades de los Estados en la Luna y en los cuerpos celestes de 1979, ${ }^{1}$ las cuales han generado vacíos legales que han puesto en peligro los principios básicos del derecho espacial y han obstaculizado el desarrollo de las actividades científicas y económicas en el espacio. Lo anterior con la finalidad de contribuir en el hallazgo de posibles soluciones que complementen las omisiones legislativas que se presentan actualmente en la regulación jurídica de la extracción y explotación de recursos naturales en el espacio, lo que prevendrá el surgimiento de conflictos internacionales y proporcionará la seguridad jurídica necesaria para fomentar el desarrollo de actividades científicas y económicas en el espacio.

Palabras clave: recursos naturales, extracción, explotación, espacio ultraterrestre, Tratado de la Luna, Tratado del Espacio, ${ }^{2}$ vacío legal, inseguridad jurídica.

\section{Extraction and exploitation of natural resources in outer space, moon and celestial bodies. A legal regulation}

\begin{abstract}
This paper analyzes the flaws present in article 11 of the 1979 Moon Treaty, which imply a number of legal loopholes that compromise the basic principles of space law, hindering the development of scientific and economic activities in outer space. It aims to contribute new legal alternatives able of circumvent the current legislative omissions that regulate outer space resource extraction, preventing international conflicts, and providing the legal certainty required to boost research and investment in outer space.

Keywords: natural resources, extraction, exploitation, outer space, Moon Treaty, Outer Space Treaty, legal loophole, legal uncertainty.

\section{Da extração e exploração de recursos naturais no espaço ultraterrestre, a Lua e os corpos celestes. Uma regulação jurídica}

\section{Resumo}

O objetivo deste trabalho é analisar as falhas que têm se apresentado nas disposições do artigo 11 do Acordo que deve reger as atividades dos Estados na Lua e nos corpos celestes de 1979, as quais têm gerado vazios legais que têm posto em perigo os princípios básicos do direito espacial e têm obstaculizado o desenvolvimento das atividades científicas e econômicas no espaço. 0 anterior com a finalidade de contribuir na descoberta de possíveis soluções que complementem as omissões legislativas que se apresentam atualmente na regulação jurídica da extração e exploração de recursos naturais no espaço, o que prevenirá o surgimento de conflitos internacionais e proporcionará a seguridade jurídica necessária para fomentar o desenvolvimento de atividades científicas e econômicas no espaço.

Palavras-chave: recursos naturais, extração, exploração, espaço ultraterrestre, Tratado da Lua, Tratado do Espaço, vazio legal, inseguridade jurídica.

1 En este escrito, cuando se haga referencia al Tratado de la Luna, se hace al Acuerdo que debe regir las actividades de los Estados en la Luna y otros cuerpos celestes.

2 En este escrito, cuando se haga referencia al Tratado del Espacio, se hace al Tratado sobre los principios que deben regir las actividades de los Estados en la exploración y utilización del espacio ultraterrestre, incluso la Luna y otros cuerpos celestes. 


\title{
De la extracción y explotación de recursos naturales en el espacio ultraterrestre, la Luna y los cuerpos celestes. Una regulación jurídica*
}

\author{
Amelia Piñeros Torres**
}

\section{SUMARIO}

Introducción - I. LOS RECURSOS NATURALES - A. Los recursos naturales en el derecho internacional - B. Los recursos naturales que se encuentran en el espacio ultraterrestre - II. LAS IMPLICACIONES DEL TRATADO DEL ESPACIO DE 1967 EN LA EXTRACCIÓN Y EXPLOTACIÓN DE RECURSOS NATURALES EN EL ESPACIO - A. Historia del Tratado del Espacio de 1967 - B. Implicaciones jurídicas que tienen los artículos I y II del Tratado del Espacio en el desarrollo de la extracción y explotación de recursos naturales en el espacio - 1. Artículo I - 2. Artículo II - III. EL ACUERDO QUE DEBE REGIR LAS ACTIVIDADES DE LOS ESTADOS EN LA LUNA Y EN LOS CUERPOS CELESTES - A. Historia del Tratado de la Luna de 1979 - B. La utilidad y eficacia del Tratado de la Luna de 1979 - IV. LAS FALLAS E IMPLICACIONES DEL ARTÍCULO 11 DEL TRATADO DE LA LUNA DE 1979 - A. Las controversias del concepto de patrimonio común de la humanidad - B. Las fallas de las disposiciones del artículo 11 del Tratado de la Luna en la regulación jurídica de la extracción y explotación de recursos naturales en el espacio - C. Las implicaciones de las fallas de las disposiciones del artículo 11 del Tratado de la Luna en el desarrollo de las actividades espaciales - V. PROPUESTA PARA CONTRARRESTAR LAS FALLAS QUE CONTIENE ACTUALMENTE EL RÉGIMEN DE EXTRACCIÓN Y EXPLOTACIÓN DE RECURSOS NATURALES EN EL ESPACIO - VI. CONCLUSIONES - Referencias

\footnotetext{
* $\quad$ Cómo citar este artículo: Piñeros Torres, A. (Diciembre, 2014). De la extracción y explotación de recursos naturales en el espacio ultraterrestre, la Luna y los cuerpos celestes. Una regulación jurídica. Revista de Derecho, Comunicaciones y Nuevas Tecnologías, 12. Universidad de los Andes (Colombia).

** Abogada y candidata a grado de Ciencia Política de la Universidad de los Andes. Coordinadora de la Especialización en Gestión Pública e Instituciones Administrativas y de la Maestría en Derecho Público para la Gestión Administrativa de la Universidad de los Andes. Correo electrónico: a.pineros265@ uniandes.edu.co
} 
Introducción

Desde mediados del siglo XX la protección al medioambiente ha sido una constante en la agenda política de la comunidad internacional, como una respuesta al desarrollo incontrolado y a la explotación sin límites de los recursos naturales (Canosa, 2004, p. 27). Esta preocupación surge como consecuencia de la importancia del medioambiente sano para garantizar la supervivencia de las generaciones presentes y futuras. Uno de los componentes esenciales para lograr dicha protección es el uso, aprovechamiento y conservación sostenible de los recursos naturales.

Específicamente, los recursos naturales son elementos necesarios para garantizar las necesidades básicas de los seres humanos, los cuales posibilitan el aseguramiento del goce de ciertos derechos, como la vida, la salud, la vivienda, entre otros. Así pues, los recursos naturales son "el sustento material del hombre y le brindan la oportunidad de desarrollarse intelectual, moral, social y espiritualmente" (Naciones Unidas, 1972, p. 1).

Desde hace varios años, el ser humano está explotando de forma desmedida los recursos naturales de la Tierra, poniendo en peligro su supervivencia. La Global Footprint Network y la New Economics Foundation (NEF) demostraron que habiendo solo transcurrido ocho meses del año 2012, la humanidad ya había agotado todos los recursos naturales que el planeta podía proveer de forma sostenible para ese año. Lo que conlleva que los seres humanos tengan que vivir en los próximos años "de futuras generaciones, sobreexplotando los recursos naturales y acumulando carbono en la atmósfera" (Pascua, 2012, párr. 2).

De esta manera, surge la necesidad de implementar medidas que protejan el medioambiente, pero a la misma vez permitan el desarrollo de las actividades que exige el mundo moderno, como por ejemplo la búsqueda de nuevas fuentes de recursos naturales por fuera de los límites terrestres. Según varios estudios científicos, el espacio tiene varios cuerpos celestes que contienen un amplio número de recursos naturales. Específicamente, en el sistema solar la Luna y el planeta Marte cuentan con una gran cantidad de recursos minerales. Así pues, la extracción y explotación de estos en el espacio aparece como una posible respuesta a su sobreexplotación y agotamiento. Por tal motivo, en los últimos años se han incrementado los deseos de enviar misiones al espacio con el fin de cumplir este objetivo (Versteeg, párr. 4).

Actualmente existen dos cuerpos normativos internacionales que regulan la extracción y explotación de recursos naturales en el espacio: el Tratado sobre los principios que deben regir las actividades de los Estados en la exploración y utilización del espacio ultraterrestre, incluso la Luna y otros cuerpos celestes, el cual establece los principios que rigen las actividades espaciales; y el Acuerdo que debe regir las actividades de los Estados en la Luna y otros cuerpos celestes, el cual regula las actividades espaciales que se puedan llegar a realizar en estos, y desarrolla los principios establecidos 
en el Tratado del Espacio que se relacionan con estas actividades.

Cabe mencionar que la eficacia del Tratado de la Luna ha sido puesta en duda por una parte de la academia y de la comunidad internacional, ya que este solo ha sido aprobado por quince Estados (Naciones Unidas, 2014) y ninguna de las principales potencias del mundo que desarroIlan actividades espaciales, como Estados Unidos, Rusia y China, lo han ratificado. Asimismo, la utilidad de este instrumento jurídico ha sido debatida, pues se ha considerado que las disposiciones que hacen referencia a los recursos naturales no son claras ni precisas respecto a la extracción y explotación de estos en el espacio, lo que ha obstaculizado e interrumpido el desarrollo económico y científico de las actividades espaciales.

En cambio, otra parte de la academia y de la comunidad internacional sostiene que no se puede desconocer la importancia que tiene esta normatividad en la evolución del derecho espacial, pues desarrolla y complementa principios que fueron establecidos en el Tratado del Espacio de 1967, e introduce nuevas disposiciones que tendrán un impacto en las futuras misiones espaciales que se dirijan hacia la Luna u otros cuerpos celestes. De igual modo, manifiestan que el problema no es la eficacia y la utilidad del Tratado de la Luna, sino la necesidad de crear un cuerpo normativo lo suficientemente claro y preciso, que permita llenar los vacíos legales que se evidencian en el régimen jurídico de extracción y explotación de recursos naturales.
Ahora bien, en los últimos años el interés en el desarrollo comercial del espacio ha aumentado, y la intención de varios Estados de viajar a la Luna y otros cuerpos celestes también, lo que ha fomentado la discusión sobre la eficacia, la utilidad y los vacíos legales del Tratado de la Luna (Coffey, 2009, p. 119). Por eso, este artículo tiene como objetivo analizar cuáles son las fallas que se han presentado en la regulación jurídica de los recursos naturales en el espacio, con la finalidad de brindar soluciones para contrarrestarlas y contribuir en la creación de un régimen legal especial que permita el desarrollo económico y científico de las actividades espaciales.

Para abordar el referido estudio, primero se expondrá qué se entiende por recursos naturales, cuál es su estatus legal en el derecho internacional y qué tipo de recursos se pueden encontrar en el espacio; seguidamente, se analizarán las implicaciones que tienen los artículo I y II del Tratado del Espacio de 1967 en la explotación y extracción de recursos naturales en el espacio; posteriormente se examinarán las fallas e implicaciones del artículo 11 del Tratado de la Luna de 1979 en la explotación y extracción de recursos naturales en el espacio; y, por último, se formulará una propuesta que contribuya en la creación de un régimen legal especial que permita el desarrollo de actividades científicas y económicas en el espacio. 


\section{LOS RECURSOS NATURALES}

\section{A. Los recursos naturales en el derecho internacional}

En la actualidad, a nivel internacional, no existe un consenso sobre el significado de la palabra recursos naturales, pues a esta se le han dado distintas definiciones, dependiendo de la materia en la cual está siendo utilizada. Aunque las definiciones son diferentes, concuerdan principalmente en que los recursos naturales son aquellos bienes y servicios que el ser humano obtiene de la naturaleza y utiliza para satisfacer sus necesidades básicas. Estos pueden ser clasificados como renovables y no renovables. Los primeros hacen referencia a los recursos que pueden reutilizarse, siempre y cuando el hombre cuide su regeneración, como el agua, el suelo, las plantas, etc.; mientras que los segundos no pueden ser renovados porque su formación natural es muy lenta y compleja, como los combustibles fósiles (Fundación Puertorriqueña de las Humanidades, párr. 3).

A pesar de que a nivel internacional hay varias definiciones de recursos naturales, el estatus legal de estos si está claramente definido. En la actualidad estos pueden ser clasificados dentro de cuatro tipos: soberanía permanente sobre Ios recursos naturales, recursos naturales compartidos, propiedad común sobre los recursos naturales y patrimonio común de la humanidad (Birnie y Boyle, 2002, p. 137). Cabe mencionar que la capacidad y libertad que tienen los Estados de explotar los recursos naturales varía dependiendo del estatus legal que estos posean.
El primero, la soberanía permanente, se encuentra consagrado en la Resolución 1803 (XVII) del 14 de diciembre de 1962 de la Asamblea General de la ONU, en la cual se establece que deberá respetarse la soberanía que ejercen los Estados sobre los recursos naturales que se encuentran dentro de su territorio. Es decir, los Estados podrán utilizar y disponer libremente de sus recursos naturales. Sin embargo, en los últimos años esta capacidad de libre disposición ha sido limitada por varios tratados internacionales que promueven la protección del medioambiente, como la Declaración de Estocolmo de 1974, la Declaración de Río de 1992, entre otros. El segundo estatus legal, recursos naturales compartidos, es una categoría intermedia en la cual los recursos no pueden ser controlados exclusivamente por un único Estado, ni pueden ser propiedad común de todos los Estados. En otras palabras, son recursos que se encuentran dentro del territorio de varios Estados vecinos, los cuales ejercen derechos compartidos sobre estos. Este estatus se encuentra establecido en la Resolución 3129 (XXVIII) del 13 de diciembre de 1973 de la Asamblea General de la ONU, en la cual se promueve la cooperación en el campo del medioambiente en materia de recursos naturales compartidos por dos o más Estados.

El tercero, la propiedad común sobre los recursos naturales, hace referencia a los recursos que se encuentran por fuera de la jurisdicción nacional de los Estados. En estos lugares, todas las naciones pueden hacer un uso legítimo y razonable de los recursos naturales, pero no podrán ser apropiados exclusivamente por un único Estado. Por último, se tiene el patrimonio 
común de la humanidad, que es similar al de propiedad común, porque en ambos casos los recursos naturales no pueden ser apoderados únicamente por un Estado, pero se diferencian en que en el primero estos deben ser conservados y explotados en beneficio de toda la humanidad. Lo que significa que todos los Estados se deben beneficiar de las actividades que se desarrollen con respecto a estos recursos, sin ningún tipo de discriminación. Este es el estatus legal que se aplica en el Tratado de la Luna de 1979 a los recursos naturales que se encuentran en el espacio ultraterrestre y en la Convención de las Naciones Unidas sobre el Derecho del Mar a los recursos que se encuentran en alta mar (Birnie y Boyle, 2002, p. 137).

\section{B. Los recursos naturales que se encuentran en el espacio ultraterrestre}

La Luna y otros cuerpos celestes del sistema solar contienen un amplio número de recursos naturales (Tronchetti, 2009, p. 5). Se ha demostrado que esta es rica en aluminio, hierro, silicio, oxigeno, hidrógeno, cromo, manganeso y potasio (Coffey, 2009, p. 121), minerales que pueden cubrir necesidades humanas en la Tierra y en futuras bases espaciales (Tronchetti, 2009, p. 5). También existe evidencia científica de que en los polos lunares hay hielo, lo que comprueba la presencia de agua en este satélite terrestre. En la actualidad no se sabe con exactitud qué cantidad de hielo existe, sin embargo, este descubrimiento es muy importante para el futuro desarrollo de la vida humana en el espacio, pues sería una fuente hídrica que podría ser utilizada para garantizar las necesidades básicas de los astronautas ("Detectan agua helada en el polo sur de la Luna", 2012).

Asimismo, se ha descubierto helio-3 en la Luna, el cual es considerado una de las principales razones por las que los Estados y las empresas privadas han mostrado un gran interés en la posibilidad de explotar los recursos que contiene este cuerpo celeste. Se estima que el helio-3 que se encuentra en la Luna podría producir diez veces más de la energía que puede generar la Tierra con carbón, petróleo y gas (Reinstein, 1999, p. 61). Además, es una energía limpia, lo que beneficiaría al medioambiente terrestre, si en algún momento se lograra explotar como fuente de energía.

Por otro lado, se ha encontrado que el planeta Marte también tiene recursos naturales que pueden ser útiles tanto en la Tierra como en el espacio. Varios de estos hallazgos se obtuvieron con la misión del robot Curiosity, que fue lanzado el 26 de noviembre de 2011 por la NASA. El objetivo principal de esta misión consiste en descubrir si el ambiente marciano habría sido propicio para la vida, y preparar las bases necesarias para una futura expedición tripulada. Se ha descubierto un alto porcentaje de agua en el suelo marciano y polvo de roca que contiene nitrógeno, oxígeno, azufre, fósforo y carbono ("De la arena de Marte se podría sacar agua”, 2013).

Aparte de esto, existen nueve mil asteroides próximos a la Tierra que contienen toneladas de hierro, níquel, oro, platino y cobalto, y que podrían ser explotados y usados por los seres humanos (Versteeg, párr. 4). También contienen 
agua helada que podría ser utilizada para el desarrollo y funcionamiento de cohetes espaciales, lo cual contribuiría en hacer los viajes al espacio más sencillos y económicos (Rizzi, 2014, párr. 10).

Actualmente existen dos empresas estadounidenses que quieren desarrollar actividades mineras en estos cuerpos rocosos. Una es Deep Space Industries (DSI), la cual tiene como objetivo, en el 2016, explorar los recursos de los asteroides y traer muestras a la Tierra a través de una nave espacial Ilamada Dragon Fly. La otra es Planetary Resources, empresa que tiene pensado, en una primera fase, enviar un telescopio cósmico para determinar cuáles son y qué composición tienen los asteroides cercanos a la Tierra. En la segunda fase, pretenden extraer y explotar los recursos naturales que se encuentren en estos (Rizzi, 2014). Por estas razones, se puede evidenciar que en el espacio ultraterrestre hay una gran cantidad de recursos naturales que podrían cubrir las necesidades básicas de los seres humanos tanto en la Tierra como en las actividades que se llegarán a desarrollar en el espacio.

Luego de haber comprendido la importancia que tienen los recursos naturales para la humanidad y de constatar que el espacio ultraterrestre es una gran fuente de estos, es necesario entrar a analizar las implicaciones jurídicas que tienen los Tratados del Espacio y de la Luna en la extracción y explotación de estos recursos.

\section{LAS IMPLICACIONES DEL TRATADO DEL ESPACIO DE 1967 EN LA EXTRACCIÓN Y EXPLOTACIÓN DE RECURSOS NATURALES EN EL ESPACIO}

\section{A. Historia del Tratado del Espacio de 1967}

La necesidad de crear un régimen jurídico espacial surgió con el lanzamiento de los primeros satélites artificiales de la Tierra durante la celebración del Año Geofísico Internacional (19571958), así como por el veloz desarrollo tecnológico de cohetes que se presentó en esa época (Kopal, 2009 p. 1). El 4 de octubre de 1957 se lanzó el primer satélite -el Sputnik 1 de la Unión Soviética-, luego de esto, comenzó una carrera espacial por la conquista del espacio ultraterrestre, "símbolo del poderío tecnológico de los países más avanzados de ese momento" (Naciones Unidas, 2007, párr. 1).

Debido a la carrera espacial que se presentó en esa época, la Organización de las Naciones Unidas (ONU) se encargó desde un principio del manejo de las iniciativas de regulación internacional de las actividades espaciales, y estableció como prioridades fundamentales el uso pacífico del espacio y el beneficio de toda la humanidad por los descubrimientos y desarrollos científicos que se pudieran lograr allí. Así pues, para alcanzar dicho objetivo la Asamblea General de la ONU creó en 1959 la Comisión sobre la Utilización del Espacio Ultraterrestre con Fines Pacíficos (COPUOS), la cual se encarga 
de la coordinación de todos los programas de cooperación sobre el espacio ultraterrestre desarrollados por la ONU y sus Estados miembros (Naciones Unidas, 2007, párr. 3).

No obstante, a pesar de la creación del COPUOS, la comunidad internacional identificó la necesidad de crear "un instrumento internacional jurídicamente vinculante que regulara la actividad espacial y evitara su incursión en las dinámicas de la guerra fría" (Araujo y Guio, 2013, p. 7). Por tal motivo, el 19 de diciembre de 1966 la Asamblea General de la ONU, a través de la Resolución 2222 (XXI), aprobó el Tratado sobre los principios que deben regir las actividades de los Estados en la exploración y utilización del espacio ultraterrestre, incluso la Luna y otros cuerpos celestes. Este tratado entró en vigencia el 10 de octubre de 1967 y estableció los principios que rigen actualmente las actividades espaciales, a saber: el principio de no apropiación del espacio, la Luna y otros cuerpos celestes; el principio de uso pacífico del espacio ultraterrestre, la Luna y otros cuerpos celestes; el principio del uso de la energía nuclear con fines pacíficos exclusivamente; el principio de no utilización de armas nucleares en el espacio ultraterrestre, la Luna y otros cuerpos celestes; el principio de cooperación internacional, y el principio de la libertad de exploración y utilización del espacio ultraterrestre, la Luna y otros cuerpos celestes en provecho e interés de todos los países, sin importar su nivel de desarrollo económico y científico.

Cabe mencionar que el Tratado del Espacio es un instrumento jurídico de principios, lo que sig- nifica que no está dirigido a resolver y regular todos los aspectos que abarca la actividad espacial, sino que es un marco legal para los futuros tratados que se expidan sobre temas espaciales más específicos. Por esta razón, el tratado fue escrito en términos generales, sin definir en muchas ocasiones los significados de los conceptos utilizados, lo que ha llevado a que estos se interpreten de diferentes maneras, lo que fomenta la discusión sobre cómo deben ser entendidas y aplicadas las disposiciones jurídicas.

\section{B. Implicaciones jurídicas que tienen los artículos I y II del Tratado del Espacio en el desarrollo de la extracción $y$ explotación de recursos naturales en el espacio}

\section{Artículo I}

Uno de los principales objetivos de los redactores del tratado era establecer un régimen legal que tuviera en cuenta no solo las necesidades, intereses y derechos de los Estados que podían desarrollar actividades espaciales en ese entonces, sino también de todos los países, sin importar su nivel de desarrollo económico y científico (Tronchetti, 2009, p. 21). Por eso se implementó en el artículo I un sistema legal que protegiera el interés común de toda la humanidad y en donde cualquier ser humano tuviera la oportunidad de disfrutar los beneficios de las actividades espaciales.

Por ende, en el artículo I se estableció el principio de libertad de acceso, exploración y utilización del espacio ultraterrestre, el cual no tuvo 
objeciones por parte de los representantes de los Estados durante las negociaciones del contenido del tratado. No obstante, no se definió el significado de la palabra uso, lo que llevó a la controversia de cómo debía interpretarse. La polémica se concentró en determinar si el uso del espacio ultraterrestre no solo hacía referencia a actividades científicas sino también comerciales. Es decir, si dentro del concepto de "uso" se podía incluir el término de "explotación" (Tronchetti, 2009, p. 22).

Igualmente, el artículo I consagra que la libertad de acceso, exploración y uso del espacio deberá hacerse "sin discriminación alguna en condiciones de igualdad", lo que significa que todos los Estados tienen los mismos derechos para acceder y utilizar el espacio, sin importar su nivel de desarrollo científico y económico. De manera que el artículo I lo que busca es que Ios Estados cumplan con el deber de explorar y utilizar el espacio ultraterrestre en beneficio de toda la humanidad, a través de la cooperación internacional.

\section{Artículo II}

El artículo II del Tratado del Espacio establece que "el espacio ultraterrestre, incluso la Luna y otros cuerpos celestes, no podrán ser objeto de apropiación nacional por reivindicación de soberanía, uso u ocupación, ni de ninguna otra manera" (1967). La naturaleza jurídica de no apropiación fue uno de los primeros principios que fueron acordados por los Estados durante el proceso de establecimiento del status legal del espacio ultraterrestre. Desde el inicio de las actividades espaciales los Estados renunciaron a cualquier tipo de reclamación territorial sobre el espacio, dado que lo consideraron como un entorno no apropiable (Tronchetti, 2009, p. 27). Específicamente, con el principio de no apropiación se busca garantizar el uso pacífico del espacio ultraterrestre y asegurar que toda la humanidad pueda beneficiarse de su uso y explotación. Así pues, los Estados no pueden extender su soberanía o reclamar derecho de propiedad sobre el espacio y los cuerpos celestes.

Aunque este principio fue aceptado por todos Ios Estados, ha sido objeto de varios debates en la academia respecto a cómo debe ser interpretado. Gran parte de estas discusiones se han concentrado en determinar si el principio de no apropiación aplica también a los particulares, pues el artículo II no lo manifiesta explícitamente. Por tal razón, algunos autores consideran que dicha prohibición solo aplica a la apropiación nacional por parte de los Estados (White, 2003 , p. 75). Sin embargo, la gran mayoría de los académicos sostienen que el principio de no apropiación también aplica a los particulares (Tronchetti, 2009, p. 29), pues cuando se redactó el artículo II los Estados eran los únicos actores capaces de desarrollar actividades espaciales, por lo que no se vio la necesidad de incluir a los actores privados en el texto de dicha disposición. Además, así el artículo II no manifieste de forma clara y precisa que dicho principio aplica a los particulares, se debe tener en cuenta que el Tratado del 67 no estableció una dicotomía entre las actividades espaciales realizadas por organismos gubernamentales y no gubernamentales, sino que consagró unos 
principios básicos que deben ser utilizados por actores públicos y privados (Tennen, 2003, párr. 8). Por eso no se puede afirmar que la ausencia de una prohibición explícita a la apropiación privada signifique que los particulares puedan ejercer derechos de propiedad en el espacio ultraterrestre. Por el contrario, debe entenderse que esta disposición se hace extensiva a los actores privados, pues si no fuera así se desconocería el objetivo del régimen espacial de garantizar el interés y bienestar de toda la humanidad.

Asimismo, el artículo 6 del Tratado del Espacio de 1967 establece que los Estados serán responsables de los actos que realicen sus nacionales en el espacio, y deberán "asegurar que dichas actuaciones se efectúen de conformidad con las disposiciones del presente Tratado". Así pues, los Estados no tienen la facultad de autorizar a sus nacionales la realización de conductas que están expresamente prohibidas para estos (Tennen, 2003, párr. 8). Por ende, las actividades que desarrollen los actores privados en el espacio deberán ser acordes con los principios establecidos en este tratado, es decir que los particulares no podrán apropiarse del espacio ultraterrestre, la Luna y otros cuerpos celestes.

Por otro lado, se debe hacer referencia al debate que ha surgido con respecto a la aplicación del principio de no apropiación sobre los recursos naturales que pueden encontrarse en el espacio. Algunos autores sostienen que dicho principio se aplica al espacio ultraterrestre como un todo, pero no específicamente sobre los recursos naturales que pueden encontrase en este, pues el artículo II no hace una referencia explícita sobre estos (Williams, 1986, p. 198). Concretamente, estos autores hacen una analogía entre las libertades establecidas en la Convención sobre la Alta Mar de 1958 y la libertad de acceso, exploración y utilización del espacio ultraterrestre del artículo I del Tratado del 67, para argumentar que dichas libertades autorizan a los Estados a apropiarse de los recursos naturales del espacio (Tronchetti, 2009, p. 31).

En contraste, otros autores consideran que el artículo II también debe ser aplicado a los recursos naturales que puedan ser extraídos del espacio y de los cuerpos celestes (Gorove, 1970, p. 74). Estos académicos piensan que no es relevante que el artículo II no mencione específicamente a los recursos naturales, pues al hablar de espacio ultraterrestre se debe entender que se está haciendo referencia a todo lo que se encuentra en este, incluso los recursos naturales que podrían llegar a ser explotados. Igualmente, consideran que la apropiación de recursos naturales para el beneficio exclusivo de quien los extraiga va en contra del artículo I del Tratado del 67, pues esta disposición establece que el uso y exploración del espacio debe ser desarrollado en beneficio e interés de toda la humanidad (Tronchetti, 2009, p. 32). Sin embargo, algunos académicos piensan que el artículo II en la actualidad restringe el desarrollo del comercio espacial, pues inhabilita a los Estados y a los particulares a explotar los recursos naturales del espacio, ya que no pueden ser apropiados (Dinkin, 2004).

Ahora bien, luego de haber analizado los artículos I y II del Tratado del 67 se puede afirmar 
que los principios contenidos en estas disposiciones determinan la naturaleza jurídica del espacio ultraterrestre como de res communis humanitatis, pues todos los Estados pueden acceder, explorar y utilizar el espacio de forma libre y sin ser víctimas de discriminación alguna, pero en beneficio de toda la humanidad y sin ejercer derechos de propiedad. En todo caso, se considera que estos fundamentos jurídicos se quedan cortos a la hora de dar una respuesta a la posibilidad de extraer y explotar los recursos naturales que hay en el espacio. No obstante, el Tratado del Espacio es un marco legal que establece de forma general los principios rectores que deberán regir los demás instrumentos jurídicos que se desarrollen sobre la materia. Razón por la cual se creó un tratado específico sobre las actividades que se pueden desarrollar en la Luna y otros cuerpos celestes, el Tratado de la Luna de 1979.

\section{EL ACUERDO QUE DEBE REGIR LAS ACTIVIDADES DE LOS ESTADOS EN LA LUNA Y EN LOS CUERPOS CELESTES}

\section{A. Historia del Tratado de la Luna de 1979}

El 25 de mayo de 1961, el presidente John F. Kennedy estableció el objetivo principal del Apolo 11, el cual consistía en realizar un aterrizaje tripulado a la Luna y regresar a la Tierra. Esta misión fue lanzada al espacio el 16 de julio de 1969 y pudo aterrizar el 21 de julio de ese mismo año. Durante la exploración, los astronautas recogieron muestras de los materiales de la superficie lunar, los cuales fueron traídos y estudiados en la Tierra (NASA, 2009). Después de ese exitoso alunizaje, el COPUOS tuvo conocimiento de que algunas piedras lunares habían sido traídas a la Tierra y que cabía la posibilidad de que algunos minerales descubiertos fueran extraídos y explotados (Tronchetti, 2009, p. 38). En ese momento el COPUOS se percató de que el Tratado del Espacio no brindaba una respuesta a las futuras actividades espaciales que se podían llegar a desarrollar en los cuerpos celestes, como la extracción y explotación de recursos naturales. Por tal razón, a comienzo de los años 70 surgió la necesidad de crear un régimen legal más detallado y específico que regulara las nuevas actividades del hombre en la Luna y los cuerpos celestes.

La creación de este régimen legal inició el 3 de julio de 1970, cuando Argentina presentó a la Subcomisión de Asuntos Jurídicos del COPUOS un borrador del acuerdo sobre los principios que deben regir la utilización de los recursos naturales de la Luna y de otros cuerpos celestes. Un año después, el 27 de mayo de 1971, la Unión Soviética propuso que se agregara un nuevo asunto a la agenda de la Asamblea General de la ONU, el cual consistía en la preparación de un tratado internacional sobre la Luna. El 4 de junio de 1971 la Unión Soviética presentó su propio borrador sobre el tratado de la Luna. El 29 de noviembre de ese mismo año la Asamblea General adoptó la Resolución 2779 (XXVI), en la que se tomó nota sobre el borrador presentado por los soviéticos, y se solicitó al COPUOS y a su Subcomisión de Asuntos Jurídicos que conside- 
raran como una prioridad la realización de un tratado sobre la Luna.

En 1979, luego de ocho años de discusiones en la Subcomisión de Asuntos Jurídicos, se logró redactar el Acuerdo que debe regir las actividades de los Estados en la Luna y otros cuerpos celestes. La Asamblea General de la ONU, en la Resolución 34/68 del 5 de diciembre de 1979, aprobó el Tratado, y desde el 18 de diciembre de ese año este estuvo abierto a la firma. Cabe mencionar que este Tratado entró a regir cinco años después de su creación, pues fue solo hasta el 11 de julio de 1984 que se depositó el quinto instrumento de ratificación en la Secretaría General de la ONU. En la actualidad, este Tratado ha sido ratificado solo por dieciséis Estados, a saber: Chile, Uruguay, Filipinas, Holanda, Austria, Australia, Pakistán, México, Marruecos, Kazakstán, Bélgica, Perú, Líbano, Turquía, Arabia Saudita y Kuwait (Naciones Unidas, 2014).

A causa de esto, varios académicos han sostenido que el bajo índice de ratificación que se ha presentado en este tratado es consecuencia de las disposiciones establecidas en el artículo 11, las cuales sostienen que la Luna y sus recursos naturales son patrimonio común de la humanidad y establecen la obligación de crear un régimen internacional que regule la explotación de estos cuando esta sea posible. Cabe mencionar que la aplicación del concepto de patrimonio común de la humanidad a los recursos naturales de la Luna y otros cuerpos celestes fue uno de los temas más debatidos durante las negociaciones del Acuerdo, debido a las repercusiones que podría llegar a tener en el futuro del desarrollo de la actividad espacial, principalmente con respecto a la explotación de los recursos naturales en el espacio (Tronchetti, 2009, p. 41).

En todo caso, en los últimos años el Tratado de la Luna ha recibido mayor atención por parte del COPUOS y otras organizaciones internacionales. Esto se debe a que el interés en el desarrollo comercial del espacio ha aumentado y la intención de varios Estados de viajar a la Luna también (Larsen y Lyall, 2009), lo que ha llevado a promover la discusión sobre la eficacia del Acuerdo y la necesidad de que este funcione.

\section{B. La utilidad y eficacia del Tratado de la Luna de 1979}

El Tratado de la Luna tiene la característica de que ha sido ratificado por muy pocos Estados en comparación con los otros instrumentos jurídicos que se han hecho sobre el derecho espacial, los cuales han recibido un apoyo generalizado. Por ejemplo, el Tratado del Espacio Ultraterrestre ha sido ratificado por 102 Estados; el Acuerdo sobre el salvamento y la devolución de astronautas y la restitución de objetos lanzados al espacio ultraterrestre por 92; el Convenio sobre la responsabilidad internacional por daños causados por objetos espaciales por 89, y el Convenio sobre el registro de objetos lanzados al espacio ultraterrestre ha sido ratificado por 60 (Naciones Unidas, 2014). Además, las principales potencias del mundo que desarrollan actividades espaciales, como Estados Unidos, Rusia y China, en la actualidad no lo han ratificado. 
Por eso varios académicos han sostenido que el Tratado de la Luna no es aceptado por la comunidad internacional, lo que ha puesto en duda su utilidad y eficacia para el derecho espacial (Araujo y Guio, 2013, p. 23). Sin embargo, no se puede desconocer la importancia y los beneficios que ha aportado esta normatividad en la evolución de las actividades espaciales, pues desarrolla y complementa principios que fueron establecidos en el Tratado del Espacio e introduce nuevas reglas y elementos que tendrán un impacto en las futuras misiones espaciales que se dirijan hacia la Luna u otros cuerpos celestes (Tronchetti, 2009, p. 40).

Igualmente, se considera que el Tratado de la Luna es relevante para la comunidad internacional, pues si no lo fuera, no hubiera sido aprobado por consenso en el COPUOS, ni adoptado por votación en la Asamblea General de las Naciones Unidas (Araujo y Guio, 2013, p. 23). Además, si este régimen legal no fuera importante los Estados nunca se hubieran puesto de acuerdo para otorgarle la categoría de tratado internacional.

Aparte de eso, se puede afirmar que el Tratado de la Luna es eficaz, pues así no haya sido ratificado por un amplio número de Estados, estos están obligados a aplicarlo y cumplirlo por las siguientes razones. En primer lugar, es necesario aclarar que en el derecho internacional no existe un organismo coercitivo que haga cumplir las leyes, pues se aplica el principio de pacta sunt servanda (Convención de Viena sobre el Derecho de los Tratados, 1969, artículo 26), el cual establece que los tratados se hacen para cumplirse. Es decir, que los Estados deben comportarse de manera tal que los objetivos que persiguen las normas y las obligaciones internacionales puedan ser satisfechas (Brotóns, 2007 , p. 564). Por tal motivo, los Estados deberán cumplir de buena fe las obligaciones contratadas (Carta de las Naciones Unidas, 1945, artículo 2.2).

En segundo lugar, el derecho espacial está sometido al derecho internacional y a la Carta de las Naciones Unidas (Naciones Unidas, 1967, artículo 3), la cual es considerada una norma de ius cogens (Convención de Viena sobre el Derecho de los Tratados, 1969, artículo 53), pues ha sido firmada por todos los Estados, y consagra valores y objetivos fundamentales de la comunidad internacional. Razón por la cual los países miembros se comprometen a cumplir los tratados que sean aprobados por la Asamblea General de la ONU. En otras palabras, las normas de ius cogens son un límite a la libertad que tienen los Estados en la concertación de sus obligaciones jurídicas, ya que establecen una opinio iuris ampliamente compartida por los miembros de la sociedad internacional (Brotóns, 2007, p. 71). Lo que lleva a que un Estado que no haya firmado ni ratificado uno de estos tratados esté obligado a ejecutarlo.

En tercer lugar, aunque las resoluciones de la Asamblea General de la ONU son meras recomendaciones, pueden llegar a incidir en la formación de normas consuetudinarias en el derecho internacional (Colmegna, 2012, p. 33). Así pues, la Corte Internacional de Justicia ha sostenido que las resoluciones de la Asamblea 
General, "[...] aunque no sean vinculantes, pueden a veces tener valor normativo. En ciertas circunstancias pueden proveer una importante evidencia para establecer la existencia de una norma o la aparición de una opinio iuris" (Corte Internacional de Justicia, 1996)). Es decir, este tipo de resoluciones pueden ser la manifestación de una norma consuetudinaria o una herramienta que contribuye en su formación.

Además, en la ONU se ha fomentado la práctica de clasificar como declaraciones las resoluciones de la Asamblea General que consagran principios de gran importancia, generando una fuerte expectativa de que serán cumplidas por los miembros de la comunidad internacional. De manera que si esta expectativa se satisface, la resolución será considerada como un mecanismo declarativo de normas obligatorias para los Estados, en virtud de la costumbre internacional (Brotóns, 2007, p. 550). Por ejemplo, la Declaración de los principios jurídicos que rigen las actividades de los Estados en la exploración y utilización del espacio ultraterrestre de 1963, la cual contiene los principios generales que caracterizan el estatuto jurídico del espacio, es considerada costumbre internacional pues goza de una amplia aceptación por parte de la comunidad internacional y ha sido acatada por los Estados que han realizado actividades en el espacio. De esta manera, gran parte de estos principios, que son considerados costumbre internacional, han sido desarrollados en el articulado del Tratado de la Luna, por lo que se puede afirmar que las disposiciones que los contienen son vinculantes para todos los Estados.
Por último, se debe mencionar que ninguno de los Estados que no han firmado ni ratificado el Tratado de la Luna ha ejercido una objeción persistente e inequívoca sobre este durante su negociación, por lo que se demuestra una aceptación tácita que reafirma su deber de observancia. Por estas razones, se considera que el Tratado de la Luna es útil y eficaz, pues así solo haya sido ratificado por quince Estados, este es de obligatorio cumplimiento y tiene fuertes repercusiones en el futuro desarrollo del derecho espacial.

\section{LAS FALLAS E IMPLICACIONES DEL ARTÍCULO 11 DEL TRATADO DE LA LUNA DE 1979}

Como se mencionó anteriormente, los principales debates que surgieron durante las negociaciones del Tratado de la Luna fueron consecuencia de las disposiciones establecidas en el artículo 11, las cuales hacen referencia principalmente a: (i) La Luna y sus recursos naturales como patrimonio común de la humanidad; (ii) El principio de no apropiación de la Luna y sus recursos naturales, y (iii) La creación de un régimen legal que regule la explotación de recursos naturales de la Luna cuando esta sea posible. Así pues, es necesario analizar estas disposiciones para poder comprender por qué el concepto de patrimonio común de la humanidad ha generado tanta controversia, cuáles han sido las fallas del artículo 11 en la regulación jurídica de la extracción y explotación de recursos naturales en el espacio, y qué implicaciones tienen en el desarrollo del derecho espacial. 


\section{A. Las controversias del concepto de patrimonio común de la humanidad}

El patrimonio común de la humanidad es un concepto que siempre ha generado controversias, pues no existe consenso entre los Estados y los académicos sobre cómo debe ser interpretado y cuál es su valor legal. Por ende, cuando este fue establecido expresamente por primera vez en el Tratado de la Luna produjo un fuerte debate, ya que los países desarrollados y en vía de desarrollo discrepaban sobre la forma en que debía interpretarse y cómo debían manejarse los recursos naturales que se encontraran en un área determinada, como patrimonio común de la humanidad (Tronchetti, 2009, p. 49).

La propuesta de declarar la Luna y sus recursos naturales como patrimonio común de la humanidad fue por primera vez hecha por el representante de Argentina en 1970. En el preámbulo del borrador del acuerdo que este país presentó ante el COPUOS, se mencionó que el Tratado del 67 no había regulado la explotación de los recursos naturales en la Luna y otros cuerpos celestes. Por esta razón, era necesario complementar el régimen espacial con una regulación específica que determinara la forma en que se debían utilizar dichos recursos. Por ende, la delegación de Argentina manifestó que la Luna y los otros cuerpos celestes debían ser considerados patrimonio común de la humanidad, pues los beneficios obtenidos por el uso de los recursos naturales debían ser distribuidos y estar disponibles para todas las personas, sin ningún tipo de discriminación (Tronchetti, 2009, p. 47). Esta propuesta fue apoyada por otros paí- ses en vía de desarrollo, que consideraban que con el establecimiento del concepto de patrimonio común de la humanidad se podría obtener alguno de estos dos resultados: que las naciones que desarrollaran actividades espaciales y explotaran recursos naturales compartieran los beneficios que obtuvieran de estas; o, que en el momento en que los países en vía de desarrollo tuvieran la capacidad de ir al espacio, todavía existieran recursos naturales disponibles que pudieran ser explotados (Gangale, 2009).

Por el contrario, la Unión Soviética estuvo en contra de la aplicación del concepto de patrimonio común de la humanidad en el Tratado de la Luna, por lo que ejerció una fuerte oposición a su inclusión en el texto normativo. Los soviéticos consideraban que el espacio y los recursos naturales que se encontraban en este eran res nullius y no res communis (Gangale, 2009). De tal forma, el 4 de junio de 1971 presentaron un borrador sobre el tratado, el cual solo hacía referencia a la Luna, no trataba el tema de la explotación de los recursos naturales y no contenía el concepto de patrimonio común de la humanidad.

En cambio, Estados Unidos, durante las negociaciones del tratado, aceptó la cláusula de patrimonio común de la humanidad; sin embargo, al final la rechazó por presiones políticas y por el fuerte lobby que ejercieron varias organizaciones espaciales en el Congreso, ya que consideraban que el Tratado de la Luna iba en contra de los intereses norteamericanos y que afectaba las posibilidades de que en un futuro se pudiera obtener provecho económico de la actividad espacial (Araujo y Chovil, 2013, p. 18). 
Por lo tanto, a causa de esta controversia el legislador internacional se vio enfrentado a un panorama de opiniones radicalmente opuestas, por lo que decidió no reglamentar un régimen especial para la explotación de los recursos naturales en el espacio. Aunque se introdujo el concepto de patrimonio común de la humanidad en el párrafo $1 .^{\circ}$ del artículo 11 , este no se aplicó de forma absoluta, pues su significado quedó circunscrito al resto del tratado y a la obligación de crear un régimen legal que regulara la explotación de recursos naturales de la Luna, cuando esta esté a punto de ser viable.

\section{B. Las fallas de las disposiciones del artículo 11 del Tratado de la Luna en la regulación jurídica de la extracción y explotación de recursos naturales en el espacio}

A pesar de que en el Tratado de la Luna de 1979 se hizo un esfuerzo por reglamentar las futuras actividades que se podrían llegar a desarrollar en el espacio, la tecnología de aquella época limitó la posibilidad de establecer disposiciones claras y específicas sobre estas, como se demuestra en el caso de la extracción y explotación de recursos naturales en el espacio. En la actualidad no se tiene certeza de cómo debe interpretarse y aplicarse el concepto de patrimonio común de la humanidad; si el principio de no apropiación aplica a los recursos naturales del espacio que han sido extraídos de su lugar de origen; si el concepto de "utilizar" que se establece en el párrafo 4 del artículo 11 solo hace referencia a actividades científicas o también comerciales; cuál es el procedimiento que debe seguirse cuando se extraigan y exploten los recursos naturales del espacio; qué entidad regulará las actividades de extracción y explotación de recursos naturales en el espacio; y cómo se asegurará la participación equitativa de todos los Estados partes en los beneficios obtenidos de los recursos naturales del espacio. Por eso, se ha considerado que este tratado no abarca ni responde temas que son de gran importancia para la comunidad internacional, como la extracción y explotación de recursos naturales, pues no regula de forma clara y precisa ciertos aspectos que son esenciales para el desarrollo de esta actividad en el espacio.

Por consiguiente, se ha considerado que ciertas disposiciones del artículo 11 son ambiguas e imprecisas, lo que ha llevado a que no se tenga certeza de cómo deben ser aplicadas e interpretadas. Por ejemplo, en el párrafo $3 .^{\circ}$ del artículo 11 no es claro si el principio de no apropiación también aplica para los recursos naturales que han sido extraídos de su lugar de origen, pues no se hace referencia explícita sobre estos. Esta incertidumbre ha dado lugar a varias interpretaciones, por un lado los países desarrollados consideran que aquellos recursos que son extraídos de su lugar de origen se convierten en propiedad de quien los extrajo. La delegación de los Estados Unidos durante las negociaciones del Tratado de la Luna sostuvo que los recursos naturales que estuvieran en la Luna o los cuerpos celestes no podían ser apropiados; sin embargo, aquellos que hubieran sido removidos sí podían ser objeto de apropiación (Naciones Unidas, 1979, p. 23). Por el otro, los países en 
desarrollo sostienen que no se puede ejercer derechos de propiedad sobre recursos naturales extraídos, pues en este caso también se aplica el principio de no apropiación (Tronchetti, 2009 , p. 55). Así pues, se puede afirmar que dicha controversia es producto de los vacíos que contiene la regulación que existe actualmente sobre la extracción y explotación de recursos naturales, en el artículo 11 del Tratado de la Luna.

Igualmente, en el literal d del párrafo $7 .^{\circ}$, que dispone que entre las principales finalidades del régimen internacional que se ha de establecer figurarán "la participación equitativa de todos los Estados Partes en los beneficios obtenidos de esos recursos", se demuestra la falta de claridad y desarrollo del artículo 11. En esta disposición el tratado no define qué se entiende por "participación equitativa" y "beneficios", lo que genera una incertidumbre a la hora de aplicar las finalidades que debe contener el nuevo régimen internacional que regulará la explotación de los recursos naturales en el espacio.

Por otro lado, el artículo 11 también falla al haber limitado el concepto de patrimonio común de la humanidad, pues este se encuentra condicionado a la obligación de establecer un nuevo régimen internacional que regule la explotación de recursos naturales cuando esta sea posible, como lo dispone el párrafo $5^{\circ}$. De manera que la propiedad común de toda la humanidad sobre la Luna, los cuerpos celestes y sus recursos naturales podría ser restringida si en un futuro se establece un régimen internacional que autorice la apropiación de estos por parte de los Estados y entidades no gubernamenta- les, razón por la cual se puede afirmar que esta limitación a la expresión del patrimonio común de la humanidad promueve la inseguridad jurídica de las actividades de extracción y explotación de recursos naturales, pues el estatus legal de estos podría cambiar en cualquier momento, modificando consigo las reglas del juego tanto para las naciones como para los actores privados, lo que llevaría al estancamiento del desarrollo de estas actividades en el espacio.

En consecuencia, se puede sostener que la falta de claridad, precisión y seguridad de las disposiciones del artículo 11 del Tratado de la Luna han conducido a la necesidad inminente de complementar y actualizar el actual régimen jurídico de extracción y explotación de recursos naturales en el espacio. Por eso, es indispensable la creación de un nuevo marco normativo que regule de forma clara y precisa la explotación de estos recursos, pues esta omisión legislativa ha obstaculizado la evolución de las actividades científicas y económicas en el espacio.

\section{Las implicaciones de las fallas de las disposiciones del artículo $11 \mathrm{del}$ Tratado de la Luna en el desarrollo de las actividades espaciales}

Las implicaciones de las fallas de las disposiciones del artículo 11 se pueden evidenciar a través del análisis de las recientes operaciones que han realizado los Estados en el espacio. Un ejemplo de esto es la misión China Chang-e3, que tiene como objetivo explorar la Luna en busca de recursos naturales, para que en un futuro se pueda establecer una base que permita la 
extracción y explotación de estos (2013). El 14 de diciembre de 2013 la sonda China alunizó exitosamente, convirtiéndose en el tercer país que logra aterrizar una nave en el satélite terrestre (Landwehr, 2013).

Aunque no se puede desconocer el triunfo de China en el desarrollo científico y tecnológico de sus actividades espaciales, es necesario preguntarse: ¿qué procedimiento legal podría aplicar para extraer y explotar los recursos naturales del espacio? ¿Qué autoridad sería la encargada de regular la extracción y explotación de estos? ¿Podría China apropiarse de los recursos naturales que ha extraído de la Luna? En la actualidad, estos interrogantes no tienen respuesta, pues el artículo 11 que consagra el régimen de extracción y explotación de recursos naturales en el espacio regula de forma superficial e incompleta estas actividades. Por esto no existe un marco normativo claro y conciso que permita a los Estados y a los particulares desarrollar este tipo de actividades, lo que obstaculiza el desarrollo económico y científico del espacio.

Por otra parte, la deficiencia, ambigüedad, imprecisión e inseguridad de las disposiciones del artículo 11 han permitido que ciertos individuos y Estados apliquen de forma equivocada el régimen jurídico espacial que se tiene actualmente, poniendo en peligro los principios de no apropiación del espacio y libertad de exploración y utilización del espacio en provecho e interés de todos los países. Para demostrar esta afirmación se puede hacer referencia a la compañía privada Lunar Embassy, la cual se dedica al mercado de los bienes raíces en el espacio
(Mejía, 2008). Esta empresa ha sido un éxito, ya que 2,5 millones de personas de casi 180 países le han comprado terrenos en el espacio (Valdeón, 2006).

A pesar de que en la página de Internet de la empresa se afirma que dichas transacciones son legales y acordes con el Tratado de 1967 (Mejía, 2008), estos negocios jurídicos violan el derecho espacial. Como se mencionó, así el artículo 2. ${ }^{\circ}$ del Tratado del Espacio no establezca explícitamente que el principio de no apropiación también aplica a los particulares, se debe entender que las actividades que estos desarrollen en el espacio deberán ser conforme a los principios consagrados en este tratado, como lo dispone el artículo sexto del mismo. Además, si en un futuro se lograra extraer y explotar recursos naturales de la Luna y otros cuerpos celestes, cabría la posibilidad de que algunos de los compradores afirmaran que también son propietarios de los recursos que se encuentran en esos terrenos y, por tanto, podrían explotarlos y sacar provecho propio de estos, con lo que se infringiría el régimen jurídico actual.

Aparte de eso, existe un grupo de congresistas norteamericanos que quieren declarar los seis lugares en los que la Nasa aterrizó en la Luna como Parques Nacionales de los Estados Unidos (Rivera, 2013). Esta idea se presentó ante el Congreso americano el pasado 8 de julio de 2013 a través del proyecto legislativo Apollo Lunar Landing Legacy Act, el cual busca proteger las zonas en las que las misiones Apollo alunizaron y los artefactos que dejaron estas de 1969 
a 1972. Principalmente se pretende asegurar estas áreas y artefactos de otras actividades espaciales que se puedan llegar a desarrollar en un futuro en la Luna, como la explotación de recursos naturales, el turismo espacial, misiones científicas, entre otras. El proyecto de ley también establece que el secretario del Departamento del Interior, en conjunto con la Nasa, administrarían los territorios de la Luna que se quieren declarar como Parques Nacionales, y buscarían que estos lugares fueran declarados patrimonio de la humanidad por la Unesco (Khan, 2013).

Aunque a primera vista se podría llegar a pensar que este proyecto tiene como fundamento el objetivo loable de proteger los lugares y artefactos de gran importancia cultural e histórica para la humanidad, se debe aclarar que su establecimiento como ley federal podría vulnerar el derecho espacial. Primero, si Estados Unidos Ilegara a declarar esos territorios de la Luna como Parques Nacionales estaría proclamando jurisdicción sobre estos. Es decir, estaría haciendo una declaración de soberanía sobre el territorio lunar, vulnerando el principio de no apropiación del espacio consagrado en el artículo $2 .^{\circ}$ del Tratado de 1967 y el párrafo $2 .^{\circ}$ del artículo 11 del Tratado de la Luna. Segundo, el establecimiento de esos parques naturales permitiría el control de estos territorios por parte de los Estados Unidos, lo que impediría que otras naciones pudieran explorar y usar sin ningún tipo de restricciones estas zonas de la Luna, infringiendo el principio de libertad de exploración y utilización del espacio en provecho e interés de todos los países.
De igual modo, no se podría descartar un posible interés por parte de los Estados Unidos en las riquezas naturales que se podrían llegar a encontrar en este satélite natural. La declaración de Parques Naturales de estas zonas lunares permitiría que el gobierno americano ejerciera jurisdicción sobre estas, lo que posibilitaría la administración y regulación de forma unilateral de todas las actividades espaciales que se pudieran desarrollar en estos territorios. Así pues, podrían establecer su propio régimen de extracción y explotación de recursos naturales, el cual les permitiría apropiarse de estos y quedarse con los beneficios obtenidos de esta actividad sin necesidad de compartirlos con los demás Estados.

Por estas razones, se evidencia la necesidad de fortalecer y complementar las disposiciones del artículo 11 a través de un nuevo marco normativo que disponga de forma clara y concisa la estructura que deberá regir la extracción y explotación de recursos naturales en el espacio, para evitar que algunos actores privados y Estados restrinjan la capacidad que tienen los demás países de explorar y utilizar la Luna y los cuerpos celestes sin ningún tipo de discriminación, lo cual proporcionaría la seguridad jurídica necesaria para fomentar el desarrollo de actividades científicas y económicas en el espacio.

A continuación se analizará la propuesta que se propone en este artículo para complementar los vacíos legales que contiene el artículo 11 del Tratado de la Luna. 
V. PROPUESTA PARA CONTRARRESTAR LAS FALLAS QUE CONTIENE ACTUALMENTE EL RÉGIMEN DE EXTRACCIÓN Y EXPLOTACIÓN DE RECURSOS NATURALES EN EL ESPACIO

Después de haber analizado las fallas que tiene actualmente el régimen jurídico de extracción y explotación de recursos naturales en el espacio, se puede concluir que la principal forma de solucionar este problema es a través del establecimiento de un marco normativo que brinde la confianza y seguridad necesaria que requieren los Estados y entidades no gubernamentales para desarrollar este tipo de actividades. No obstante, una de las características del derecho espacial es su flexibilidad, ya que se encuentra en constante cambio debido al incesante desarrollo de la tecnología espacial (Kopal y Verschoor, 2008, p. 4). Por esta razón, el derecho espacial está conformado principalmente por principios generales que han sido aplicados en los diversos desarrollos tecnológicos espaciales que se han presentado a lo largo del tiempo.

A causa de esto, se propondrá el establecimiento de unos principios que podrían ser parte del nuevo marco normativo de extracción y explotación de recursos naturales, para contrarrestar la ambigüedad, imprecisión e inseguridad que caracteriza actualmente al artículo 11 del Tratado de la Luna. Cabe mencionar que las directrices que se propondrán en este trabajo son de naturaleza general y flexible, ya que en este momento se está desarrollando la tecnología espacial necesaria para extraer y explotar recursos naturales en el espacio. De manera que para poder establecer normas más particulares y específicas en el nuevo marco normativo, los científicos deberán tener lista la tecnología que permita el desarrollo de esta actividad en el espacio.

Antes de exponer los principios que debería contener el nuevo marco normativo, se debe hacer referencia a la limitación que consagra el párrafo primero del artículo 11, ya que se considera que el concepto de patrimonio común de la humanidad no debería estar condicionado al establecimiento de un nuevo régimen internacional que regule la extracción y explotación de recursos naturales cuando esta sea posible. Es decir, este debería respetar la propiedad común de toda la humanidad sobre la Luna, los cuerpos celestes y sus recursos naturales. Por tal motivo, se considera que se debería hacer una enmienda al párrafo primero del artículo 11, con la finalidad de eliminar la restricción que consagra dicha disposición sobre el concepto de patrimonio común de la humanidad.

De tal forma se evitaría que en un futuro se estableciera un régimen internacional que autorizara a los Estados y entidades no gubernamentales apropiarse de la Luna y los cuerpos celestes, puesto que estos deben ser conservados y explotados en beneficio de toda la humanidad. Asimismo, el concepto de patrimonio común de la humanidad, al no estar condicionado a la creación de un nuevo marco normativo, permitiría que los Estados o entidades no gubernamentales que decidieran extraer y explotar recursos naturales en el espacio tuvieran las reglas del 
juego claras desde un principio, promoviendo de tal forma la seguridad jurídica y el desarrollo de estas actividades en el espacio.

Ahora se expondrán los principios que debería contener el nuevo marco normativo de extracción y explotación de recursos naturales en el espacio. En primer lugar, uno de estos principios debe indicar que el concepto de "utilizar" que se establece en el párrafo 4 del artículo 11 del Tratado de la Luna no solo hace referencia a actividades científicas sino también comerciales, ya que en los últimos años se ha presentado un incremento en el desarrollo de actividades económicas en el espacio. Específicamente, a partir del año 2003 se dejó atrás el orden bipolar que regía el espacio ultraterrestre y se pasó a un nuevo sistema, caracterizado por la globalización espacial (Riess, 2005, p. 177). En la actualidad, no solo Estados Unidos y Rusia están enviando misiones al espacio sino también China, India, Corea del Sur y la Unión Europea. Además, hoy en día el número de países que utilizan la tecnología espacial para prestar servicios de información y telecomunicación ha aumentado (Blasi, 2014).

Aparte de eso, cada vez más empresas privadas quieren ingresar a los negocios que generan las distintas actividades que se pueden desarrollar en el espacio, como los seguros espaciales, las telecomunicaciones por satélite, el turismo espacial, entre otros. Por estas razones, se considera que el concepto de "utilizar" no puede hacer referencia solamente a actividades científicas sino también comerciales, ya que en este momento no se puede desconocer que el interés por la exploración y utilización del espacio no solo abarca un ámbito científico sino también económico. Así pues, se debe crear un principio que permita la utilización del espacio con fines comerciales, siempre y cuando esta se haga en provecho y en interés de todos los países, sea cual fuere su grado de desarrollo económico y científico, y se respete la capacidad que tienen todos los Estados de explorar y utilizar la Luna y los cuerpos celestes sin ningún tipo de discriminación.

En segundo lugar, el nuevo cuerpo normativo que se propone en este trabajo debe incluir un principio que regule la participación de las entidades no gubernamentales en la extracción y explotación de recursos naturales en el espacio, pues en los últimos años varias empresas privadas han estado trabajando en proyectos relacionados con este tema (Rizzi, 2014, párr. 7). Por eso, los Estados deben discutir sobre la regulación que debe aplicarse al aumento de la participación de las entidades no gubernamentales en las actividades que se puedan desarrollar en el espacio ultraterrestre (Castro, 2001, p. 110), ya que no se puede olvidar que son los Estados quienes responden internacionalmente por las actividades nacionales que realicen en el espacio, la Luna y otros cuerpos celestes las entidades no gubernamentales (Naciones Unidas, 1967).

Cabe mencionar que la necesidad de implementar este tipo de legislación nacional ya se había evidenciado en la comunidad internacional. La Resolución 59/115 del 10 de diciembre de 2004 de la Asamblea General de la ONU reco- 
mienda a los Estados "promulgar y aplicar legislación nacional por la que se autorice y disponga la supervisión continua de las actividades que lleven a cabo en el espacio ultraterrestre las entidades no gubernamentales que se encuentren bajo su jurisdicción".

A pesar de que cada Estado tiene la autonomía y libertad de redactar su legislación nacional como desee, sería conveniente que todas las naciones se pusieran de acuerdo respecto al contenido de las normas internas que supervisen y controlen la actividad de extracción y explotación de recursos naturales por parte de las entidades no gubernamentales en el espacio (Gerhard, 2005, p. 84). De esta manera, se logaría un orden justo y equitativo para todos los privados que participen en este tipo de actividad espacial y se protegería el objetivo del régimen espacial de garantizar el bienestar de toda la humanidad, ya que el interés particular de las entidades no gubernamentales se vería limitado por la obligación de explorar y utilizar el espacio ultraterrestre de forma responsable y en provecho de todos los Estados (Gerhard, 2005, p. 87).

En tercer lugar, este nuevo marco normativo debe contener un principio que solucione la controversia que existe actualmente sobre si es posible que los Estados y las entidades no gubernamentales se apropien de los recursos naturales que son extraídos de su lugar de origen. Para comenzar, se debe aclarar que la extracción y explotación de recursos naturales será una actividad muy costosa que no solo tendrá intereses científicos sino también comerciales. Por esta razón, los Estados y las entidades no gubernamentales que lleguen a participar en este tipo de proyectos buscarán obtener una utilidad por los esfuerzos, mano de obra y capital invertidos, y por los riesgos asumidos al extraer y explotar dichos recursos.

A causa de esto, se puede afirmar que el desarrollo de este tipo de actividad espacial se vería obstaculizado si los Estados y actores privados no pudieran apropiarse de los recursos naturales extraídos de su lugar de origen, ya que no estarían dispuestos a invertir el tiempo, la mano de obra ni el capital que esta actividad requiere, pues no tendrían la certeza de obtener algún beneficio. Por eso, es esencial armonizar el interés particular de apropiarse de los recursos explotados y el interés general de que todos los Estados tengan una participación equitativa en los beneficios obtenidos de dicha actividad (Naciones Unidas, 1979, artículo 11).

De manera que sería una buena idea incluir en el marco normativo la propuesta hecha por Carolina Araujo y Armando Guio (2013) de plantear un régimen similar al establecido por el principio $12 .^{\circ}$ de la Resolución 41/65 de 1986 de las Naciones Unidas sobre la teleobservación de la Tierra. Estos autores plantean:

Un régimen que consagre el derecho que tienen todos los países del mundo, particularmente los países en desarrollo, a un acceso justo y equitativo, no solo a los beneficios que se deriven de esa explotación de recursos, sino a los recursos mismos, pero a un costo razonable que al mismo tiempo atienda las necesidades especiales de los países en desarrollo. (Araujo y Guio, 2013, p. 38) 
Es decir, los países en desarrollo podrán acceder a los recursos $y / 0$ beneficios que se obtengan de la explotación de estos, pero deben pagar un costo razonable a los países desarrollados o entidades no gubernamentales que invirtieron tiempo, mano de obra y capital en la realización de esta actividad.

De esta forma, se lograría conciliar entre el interés particular y general, lo que garantizaría una utilidad para el Estado o empresa que explote los recursos naturales y una participación equitativa de los demás Estados en los beneficios adquiridos de dicha explotación.

Por último, el marco normativo que se propone en este trabajo debería incluir un principio que haga referencia al establecimiento de una autoridad internacional que administre, vigile y controle el régimen de extracción y explotación de recursos naturales en el espacio. Por este motivo, la creación de una organización internacional sería una buena idea para fomentar la cooperación internacional (Urueña, 2008, p. 49), ya que es esencial la colaboración entre todos los Estados para garantizar que la exploración y utilización del espacio se haga con fines pacíficos y en provecho de toda la humanidad. De esta manera, la organización internacional podría contribuir en: el diseño de las discusiones que se Ilevarían a cabo entre los Estados para determinar el contenido de la legislación interna que regule la participación de las entidades no gubernamentales en la extracción y explotación de recursos naturales; el establecimiento del costo razonable que debería pagar cada Estado para poder acceder a los recursos naturales explotados y/o a los beneficios obtenidos de estos; vigilar que todos los Estados y entidades no gubernamentales que extraigan y exploten recursos naturales respeten los principios consagrados en el Tratado del Espacio de 1967; entre otros.

\section{CONCLUSIONES}

El mundo moderno se caracteriza por los constantes desarrollos tecnológicos que tienen por finalidad mejorar la calidad de vida de los seres humanos a través de su bienestar, seguridad y estabilidad. Para poder mantener este nivel de vida los Estados han tenido que explotar de forma excesiva los recursos naturales que se encuentran en la Tierra. Esta situación ha llevado a que gran parte de las fuentes de recursos naturales que existen en el mundo hoy en día se estén agotando. De manera que ha surgido la necesidad de buscar nuevas fuentes de recursos naturales diferentes a las que se encuentran en la Tierra, como por ejemplo en el espacio ultraterrestre. Varias investigaciones científicas han determinado que el espacio contienen un amplio número de recursos naturales, como agua, hierro, níquel, platino, cobalto, helio-3, entre otros.

Actualmente existe el Tratado de la Luna de 1979 que regula las futuras actividades espaciales que se puedan llegar a desarrollar en la Luna y los cuerpos celestes. Este tratado solo ha sido aprobado por quince Estados y ninguna de las principales potencias del mundo que desarrollan actividades espaciales lo ha ratifi- 
cado, por lo que varios académicos han puesto en duda su utilidad y eficacia para el derecho espacial. Sin embargo, no se puede desconocer la importancia de este instrumento jurídico y los beneficios que ha generado, ya que ha complementado principios que fueron establecidos en el Tratado de 1967 y ha incorporado nuevas disposiciones que regularán las futuras misiones espaciales que se envíen al espacio.

En todo caso, el artículo 11 del Tratado de la Luna ha sido el que mayor controversia ha desatado, pues establece las normas que regulan la extracción y explotación de recursos naturales en el espacio. Estas disposiciones se han caracterizado por ser imprecisas e inseguras, lo que ha generado la necesidad de crear un nuevo marco normativo que complemente los vacíos legales que estas han originado, puesto que la falta de claridad y certeza de este artículo ha llevado a que ciertos Estados y entidades no gubernamentales apliquen e interpreten de forma errónea el régimen jurídico de extracción y explotación de recursos naturales, vulnerando los principios básicos del derecho espacial y obstaculizando el desarrollo de diversas actividades en el espacio.

Por lo tanto, el marco normativo de extracción y explotación de recursos naturales que se propone en este escrito está conformado por unos principios que buscan contrarrestar la imprecisión e inseguridad jurídica que caracteriza actualmente al artículo 11. Estos principios tienen una naturaleza general y flexible, ya que en este momento se está desarrollando la tecnología espacial necesaria para extraer y explotar recur- sos naturales del espacio. Así pues, los principios que se consideran que deberían conformar el régimen jurídico son los siguientes:

1. Los Estados, las organizaciones internacionales intergubernamentales o no gubernamentales, las organizaciones nacionales o entidades no gubernamentales tienen derecho a explorar y utilizar el espacio ultraterrestre, la Luna y los cuerpos celestes con fines científi$\cos$ y/o comerciales, siempre y cuando estas se hagan en provecho e interés de toda la humanidad y se respete la capacidad que tienen todos los Estados de explorar y utilizar el espacio ultraterrestre, la Luna y los cuerpos celestes sin ningún tipo de discriminación.

2. Los Estados deben adoptar normas nacionales que supervisen y controlen la actividad de extracción y explotación de recursos naturales en el espacio, la Luna y otros cuerpos celestes por parte de las entidades no gubernamentales, para garantizar la exploración y utilización del espacio de forma libre, responsable y en provecho de toda la humanidad.

3. Los Estados, las organizaciones internacionales intergubernamentales o no gubernamentales, las organizaciones nacionales o entidades no gubernamentales podrán apropiarse de los recursos naturales que extraigan y exploten del espacio ultraterrestre, la Luna y los cuerpos celestes, siempre y cuando permitan que los demás Estados, especialmente los que se encuentran en vía de desarrollo, puedan tener un acceso equitativo y justo a los recursos y/o beneficios que se obtengan 
de la explotación de estos, a través del pago de un costo razonable.

4. Cuando la extracción y explotación de recursos naturales en el espacio, la Luna y los cuerpos celestes sea factible, los Estados deberán conformar una organización internacional que administre, vigile y controle dicha actividad, con el objetivo de promover la cooperación internacional.

En conclusión, la aplicación de este marco normativo puede ayudar a corregir las fallas que caracterizan actualmente las disposiciones del artículo 11, ya que este contribuye a regular de una forma más clara y concisa los asuntos que conciernen la extracción y explotación de recursos naturales en el espacio. Esto evitaría el surgimiento de confusiones y conflictos en la comunidad internacional y, proporcionaría la seguridad jurídica necesaria para fomentar el desarrollo de actividades científicas y económicas en el espacio.

\section{Bibliografía}

Araujo Chovil, C. y Guio Español, A. (2012). El régimen jurídico de la Luna y otros cuerpos celestes (tesis de pregrado). Universidad de los Andes, Bogotá, Colombia.

Asamblea General de las Naciones Unidas (1961). Cooperación internacional en la utilización del espacio ultraterrestre con fines pacíficos. Aprobada por la Resolución 1721, de 20 de diciembre de 1961. Recuperado de http://www.oosa.unvienna.org/pdf/publications/st_space_11rev2S.pdf

-- (1962). Soberanía permanente sobre los recursos naturales. Aprobada por la Resolución 1803 (XVII), de 14 de diciembre de 1962. Recuperado de http://www.tc.gob.pe/tratados/ uni_ddhh/instru_alca_especifi_uni/instru_ dere_civ/libre_deter/resol_1803.pdf

--- (1963). Declaración de los principios jurídicos que deber regir las actividades de los Estados en la exploración y utilización del espacio ultraterrestre. Aprobada por la Resolución 1962 (XVIII), de 13 de diciembre de 1963. Recuperado de http://www.oosa.unvienna. org/pdf/publications/st_space_11rev2S.pdf

--- (1966). Tratado sobre los principios que deben regir las actividades de los Estados en la exploración y utilización del espacio ultraterrestre, incluso la Luna y otros cuerpos celestres. Aprobada por la Resolución 2222 (XXI), de 19 de diciembre de 1966. Recuperado de http://www.un.org/es/comun/ docs/?symbol=A/RES/2222(XXI)\&Lang=S\&A rea $=$ RESOLUTION

--- (1970). Declaración de principios que regulan los fondos marinos y oceánicos y su subsuelo fuera de los límites de la jurisdicción nacional. Aprobada por la Resolución 2749 (XXV), de 17 de diciembre de 1970. Recuperado de http://editguardacostaspna.org.ar/archivos/ espacios-maritimos/Resolucion_2749.pdf 
--- (1971). Elaboración de un tratado internacional concerniente a la Luna. Aprobada por la Resolución 2779 (XXVI), de 29 de noviembre de 1971. Recuperado de http://www.un.org/ es/comun/docs/?symbol=A/RES/2779(XXVI )\&Lang=S\&Area $=$ RESOLUTION

--- (1973). Cooperación en el campo del medio ambiente en materia de recursos naturales compartidos por dos o más Estados. Aprobada por la Resolución 3129 (XXVIII), de 13 de diciembre de 1973. Recuperado de http:// www.un.org/es/comun/docs/?symbol=A/RE S/3129(XXVIII)\&Lang=S\&Area=RESOLUTION

-- (1979). Acuerdo que debe regir las actividades de los Estados en la Luna y otros cuerpos celestes. Aprobada por la Resolución 34/68, de 5 de diciembre de 1979. Recuperado de file:///Users/Ame/Downloads/ ARES_34_68S.pdf

--- (1986). Principios relativos a la teleobservación de la Tierra desde el espacio. Aprobada por la Resolución 41/65, de 3 de diciembre de 1986. Recuperado de http://www.un.org/ es/comun/docs/?symbol=A/RES/41/65

-- (2004). Aplicación del concepto de "Estado de lanzamiento". Aprobada por la Resolución 59/115, de 10 de diciembre de 2004. Recuperado de http://www.un.org/ en/ga/search/view_doc.asp?symbol=A/ RES/59/115\&Lang=S

Birnie, P. y Boyle, A. (2002). International Law \& the Environment. United States: Oxfor University Press.
Blasi, R. (16 de enero de 2014). La América Bolivariana se lanza a conquistar el espacio. INFOBAE. Recuperado de http://www.infobae. com/2014/01/16/1537546-la-america-bolivariana-se-lanza-conquistar-el-espacio

Brotóns, A. (2007). Derecho Internacional. Valencia: Tirant Lo Blanch.

Canosa Usera, R. (2004). Constitución y Medio Ambiente. Lima: Jurista Editores.

Castro Villalobos, J. (2001). La Tercera Conferencia de las Naciones Unidas sobre el Espacio Ultraterrestre y el Derecho. Anuario Mexicano de Derecho Internacional , 1, 97-119.

Christol, C. (1994-1995). Space Law: Its commercial implications. Australian International Law Journal , 30-35.

Centro de Asuntos de Desarme de las Naciones Unidas (1994). Estudio sobre la aplicacion de medidas de fomento de la confianza en el espacio ultraterrestre. Nueva York: Naciones Unidas.

Coffey, S. (2009). Establishing a legal framework for property rights to natural resources in outerspace. Case Western Reserve Journal of International Law, 41, 119-147.

Colmegna, P. (2012). Impacto de las Normas de Soft Law en el desarrollo del Derecho Internacional de los Derechos Humanos. Revista Electrónica del Instituto de Investigaciones Smbrosio L. Gioja (8), 27-47. 
Corte Internacional de Justicia (1996). Opinión consultiva sobre la licitud de la amenaza o el uso de armas nucleares por un Estado en un conflicto armado. Recuperado de http:// www.icj-cij.org/homepage/sp/advisory/advisory_1996-07-08.pdf

De la arena de Marte se podría sacar agua (27 de septiembre de 2013). El Tiempo. Recuperado de http://www.eltiempo.com/archivo/ documento/CMS-13086446

Detectan agua helada en el polo sur de la Luna (20 de junio de 2012). ABC. Recuperado de http://www.abc.es/20120620/ ciencia/abci-confirman-agua-helada-luna-201206201805.html

Dinkin, E. (2009). Property Rights and Space Commercialisation. From The Space Review: http://www.thespacereview.com/article/141/1

Fundación Puertorriqueña de las humanidades. Enciclopedia de Puerto Rico. Recuperado de http://www.enciclopediapr.org/esp/article. cfm?ref $=08032702$ \&highlight $=\% 2$ Brecurs os\%20\%2Bnaturales

Gangale, T. (2009). The Development of Outer Space: Sovereignty and Property Rights in International Space Law. Santa Barbara: Praeger.

Gerhard, M. (2005). National Space Legislation: Perspectives fo Regulating Private Space Activities. In Essential Air and Space Law of Outer
Space (Marietta Benkö ed., pp. 75-90). Holanda: Eleven International Publishing.

Hernández, A. (2007). El Concepto de desarrollo sostenible en el Derecho internacional. Recuperado de http://www.upf.edu/orbis/_pdf/ ARodrigo/Rodrigo_2007_3.pdf

India sends mission to Mars (5 de noviembre de 2013). The New York Times. Recuperado de http://india.blogs.nytimes. com/2013/11/05/india-sends-missionto-mars/?_php=true\&_type=blogs\&_ php $=$ true\&_type=blogs \&ref $=$ marsplanet $\&$ _ $r=1$

Khan, A. (11 de julio de 2013). National park on the moon at Apollo landing sites: A loony idea? Los Angeles Times. Recuperado de http://articles.latimes.com/2013/jul/11/ science/la-sci-sn-moon-national-park-lunarbill-20130711

Kopal, V. y Diederiks, V. (2008). An Introducttion to Space Law. Holanda: Kluwer Law International.

Lafranco Vásquez, M. y Miranda, M. Proyecto: Diccionario del Pensamiento Alternativo II. Recuperado de http://www.cecies.org/articulo. $\operatorname{asp}$ ? $\mathrm{id}=222$

Landwehr, A. (14 de diciembre de 2013). La liebre llegó a la Luna: ¿cuándo le seguirá un astronauta chino? El País Costa Rica. Recuperado de http://elpais.cr/frontend/noticia_ detalle/8/88884 
Lazarus, R. (2004). Environmental Law. United States: The Universoty of Chicago Press.

Llegada del robot Curiosity a Marte abre una nueva era. Revista Semana. Recuperado de http://m.semana.com/vida-moderna/articulo/llegada-del-robot-curiosity-marte-abrenueva/262533-3

Mejia, M. (2008). Prosperidad Privada y Soberanía en el Espacio. Mexico. Recuperado de http://biblio.juridicas.unam.mx/libros/6/2790/9.pdf

Naciones Unidas (1945). Carta de las Naciones Unidas. Recuperado de http:// www.acnur.org/t3/fileadmin/scripts/doc. php?file=biblioteca $/$ pdf $/ 0002$

--- (1969). Convención de Viena sobre los derechos de los tratados. Recuperado de https:// www.oas.org/dil/esp/Convencion_de_Viena_ sobre_derecho_tratados_Colombia.pdf

--- (1979). Committee on the Peaceful Uses of Outer Space. Recuperado de http://www. oosa.unvienna.org/pdf/transcripts/copuos/ AC105_PV203E.pdf

--- (1972). Declaración de Estocolmo sobre el medio ambiente humano. Recuperado de http://www.ordenjuridico.gob.mx/TratInt/Derechos\%20Humanos/INST\%2005.pdf

--- (2007). Instrumentos internacionales para el uso pacífico del espacio ultraterrestre. Recuperado de http://www.cinu.org.mx/temas/ Derint/espacio.htm
NASA (2004). The vision for space exploration. Recuperado de http://www.nasa.gov/ pdf/55583main_vision_space_exploration. pdf

--- (2009). Apollo 11 mission. Recuperado de http://www.nasa.gov/mission_pages/apoIlo/missions/apollo11.html\#.U-UnHIB5M-h

Pascua, A. (23 de agosto de 2012). La humanidad ya ha agotado su presupuesto ecológico anual. El Mundo. Recuperado de http://www. elmundo.es/elmundo/2012/08/23/natura/1345717625.html

¿Qué busca China en la Luna? (2 de diciembre de 2013). BBC. Recuperado de http://www.bbc.co.uk/mundo/noticias/2013/12/131202_ciencia_espacio_ china_sonda_exploracion_luna_np.shtml

Riess, C. (2005). International Cooperation Patterns and Trends of Future Space Regulationes. En M. Benkö, Essential Air and Space Law. Holanda: Eleven International Publishing.

Rivera, A. (3 de diciembre de2013). EEUU defiende su patrimonio histórico cultural en la Luna. El País. Recuperado de http://sociedad.elpais.com/sociedad/2013/12/03/actualidad/1386101599_632530.html

Rizzi, P. (21 de enero de 2014). El espacio: ¿fuente y origen del oro en el mundo? Discovery Channel. Recuperado de http://noticias. 
tudiscovery.com/el-espacio-fuente-y-origendel-oro-en-el-mundo/

Se acelera el consumo de los recursos naturales (13 de mayo de 2011). BBC. Recuperado de http://www.bbc.co.uk/mundo/noticias/2011/05/110513_verde_recursos_naturales_Ih.shtml

Tronchetti, F. (2009). The Exploitation of Natural Resources of the Moon and Other Celestial Bodies: a Proposal for a Legal Regime. Recuperado de http://books.google.com.co/ books? $\mathrm{id}=2-\mathrm{DU} 3 Z \mathrm{BrKhEC} \&$ printse $=$ frontco ver\&hl=es\&source=gbs_ge_summary_r\&cad $=0 \# v=$ onepage $\& q \& f=$ false

Ureña, R. (2008). Derecho de las Organizaciones Internacionales. Bogotá: Ediciones Uniandes.
Valdeón, J. (27 de agosto de 2006). El hombre que vende la Luna. El Mundo. Recuperado de http://www.elmundo.es/suplementos/cronica/2006/565/1156629605.html

Versteegm, B. Minería espacial al alcance de la mano. National Geographic. Recuperado de http://www.nationalgeographic.es/noticias/ ciencia/espacio/minera-espacial-al-alcancede-la-mano

Williams, M. (1986). The Exploration and Use of Natural Resources in the Law if the Sea abd the Law of the Outer Space. In Proceedings of the Twenty-Ninth Colloquium on the Law of Outer Space. 